\title{
Preliminary Screening of Sapindus mukorossi Extracts from Different Sources against Forest Fungi
}

\author{
Prerana Badoni ${ }^{1 *}$, Y.P. Singh ${ }^{2}$, Vineet Kumar ${ }^{3}$, Kartik Uniyal ${ }^{4}$ \\ ${ }^{1}$ Assistant Professor, Department of Microbiology, Uttaranchal College of Science \& Technology, Dehradun, \\ India \\ ${ }^{2}$ Retd. Scientist, Forest Pathology Division, Forest Research Institute, Dehradun, India \\ ${ }^{3}$ Scientist, Chemistry Division, Forest Research Institute, Dehradun, India \\ ${ }^{4}$ Assistant Professor, Department of Biotechnology/Microbiology, Alpine Institute of Management \& Technology,
} Dehradun, India

\begin{abstract}
*Address for Correspondence: Dr. Prerana Badoni, Assistant Professor, Department of Microbiology, Uttaranchal College of Science \& Technology, Dehradun-248001, India
\end{abstract}

E-mail: prerana.badoni@gmail.com

Received: 23 Jul 2018/ Revised: 19 Nov 2018/ Accepted: 22 Feb 2019

\begin{abstract}
Background: Secondary metabolites of the plant have shown antimicrobial activity. Saponins, from pericarp of S. mukorossi have been reported to possess antimicrobial efficacy against a variety of bacteria and fungi. The present study entails to asses this efficacy against different forest fungi.

Methods: Seeds of S. mukorossi, a medicinal plant of family Sapindaceae, collected from different sources viz. Dehradun and Gyarahdevi (Uttarakhand) and Nainatikker (Himachal Pradesh) were tested for their antifungal properties on the basis of IC $\mathrm{C}_{50}$ Chloroform and methanol extract of fruit pericarp from three sources of soap nut were assayed against eight forest fungi using poisoned food technique. Both the extracts were screened at four concentrations of $0.5 \%, 1.0 \%, 1.5 \%$, and $2 \%$.

Results: In our screening, we have found that chloroform extract of all sources registered $\mathrm{IC}_{50}$ at all concentrations against Phoma sp. and $P$. dalbergiae whereas, methanol extract of all the three sources attained $I C_{50}$ at all concentrations against $P$ homa sp., $P$. dalbergiae, $R$. solani and $T$. piluliferum. IC 50 was not achieved against $A$. alternata and $F$. oxysporum at any concentration of the sources in both the extracts.

Conclusion: It can be concluded from the present study that though saponins of soap nut tree have many useful biological activities but chloroform and methanol extracts do not contain comparable biological activity against common forest fungi.
\end{abstract}

Key-words: Antifungal activity, Forest fungi, $I C_{50}$, Pericarp, Poisoned food technique, Seed sources

\section{INTRODUCTION}

The Plant Kingdom has been the safeguard for the humans throughout recorded history. The importance of medicinal plants is gaining attention because of this resumption of interest. However, this is occurring while natural habitats in countries of origin are being lost. It is determined that there are about 2,500,000 species of higher plants and the majority of these have remained

\section{How to cite this article}

Badoni P, Singh YP, Kumar V, Uniyal K. Preliminary Screening of Sapindus mukorossi Extracts from Different Sources against Forest Fungi. SSR Inst. Int. J. Life Sci., 2019; 5(2): 2244-2258.

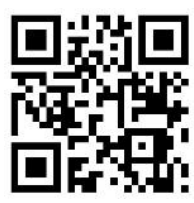

Access this article online https://iijls.com/ un-examined in detail for their pharmacological activities ${ }^{[1]}$. Medicinal plants are a source of great economic value in the Indian subcontinent. Nature has given us a very rich botanical wealth with diverse varieties of plants growing in different parts of the country ${ }^{[2]}$.

Higher plants harbor numerous compounds which provide resistance to pathogenic organisms. Towards solving the antimicrobial resistance issue, drivers of resistance and possible solutions have been listed for future approaches. Discovery and development of new antimicrobial agents that have clinical significant importance from natural resources could be one of the effective approaches. It is important to discover new antimicrobial agents in order to replace currently available antimicrobials ${ }^{[3]}$. 
During the course of evolution, the selection pressure caused by pathogens has probably been highly acute and followed the vast chemical diversity in plants. Secondary compounds from plants are guaranteed to have biological activity, protecting the plant from pathogens. Information of the pests to which the secondary compounds produced in the plants are resistant may provide useful leads in predicting which pests may be controlled by compounds from a particular plant species. This approach has conducted the discovery of different botanical pesticides ${ }^{[4]}$.

Sapindus mukorossi Gaerten (Family: Sapindaceae), a medicinal plant, commonly known as Ritha or areetha was found throughout India. The fruit contains saponins (10-11.5\%), sugars (10\%) and mucilages ${ }^{[5]}$. The fruits of the plant are valued for saponins present in plants, which consists of $56.5 \%$ of the drupe. Saponins have been isolated from the pericarp. Saponins exhibit potent antifungal property and are often present in relatively high levels in healthy plants; therefore these molecules have been implicated as determinants of plants resistance to fungal attack. Fungi that invade saponin containing plants must have strategies for protecting themselves from host saponins. For many fungi, saponin resistance may be a prerequisite for successful infection [6].

It was reported that saponins extracted from the fruit pericarp of $S$. mukorossi had bactericidal/bacteriostatic property against $L$. acidophilus ${ }^{[7]}$. It was also found that ethanol and chloroform extracts of S. mukorossi showed antibacterial activity against Helicobacterium pylori ${ }^{[8]}$. Pericarps of $S$. mukorossi exhibited potent antimicrobial activities on dermatophytes, Epidermophyton floccosum, Trichophyton mentagrophytes, T. rubrum, Sabouraudites canis and C. albicans ${ }^{[9]}$.

The present study is based upon the provenance study of S. mukorossi collected from three different sources i.e. Forest Research Institute, Dehradun and Gyarahdevi, Pithoragarh, Uttarakhand and Nainatikker, Sirmaur, Himachal Pradesh. The main objective of this study was to test two extracts (Chloroform and methanol) of $S$. mukorossi from different sources for antifungal properties on the basis of $\mathrm{IC}_{50}$. Most importantly, antifungal activity of chloroform and methanol extracts of fruit pericarp was reported for the first time in this paper.

\section{MATERIALS AND METHODS}

Preparation of fruit pericarp extracts- The present study was carried out in October 2011 in Forest Pathology Division, Forest Research Institute, Dehradun, Uttarakhand, India.

For the preparation of extracts, pericarp was separated from seeds. The collected pericarp was spread on blotter paper sheet and air-dried in shade. The dried pericarp was then cut into pieces and extracted successively with the solvents of increasing polarity viz. chloroform and methanol in a Soxhlet apparatus. These extracts were concentrated on a water bath to small volumes ${ }^{[10]}$. The yield of extracts was determined on moisture free basis (Table 1). Eight forest fungi were selected for bioassay viz. Alternaria alternata, Colletotrichum gloeosporioides, Phoma sp., Phomopsis dalbergiae, Ganoderma lucidum, Fusarium oxysporum, Rhizoctonia solani, and Trichoderma piluliferum. The rationale for short-listing these fungi is ecological, host specificity, plant part infectivity, wider presence, economic and loss, etc.

Table 1: Yield of extracts (\%) from different sources of $S$. mukorossi

Source/Yield (\%)

\begin{tabular}{cccc} 
Extract & Dehradun & Gyarahdevi & Nainatikker \\
\cline { 2 - 4 } & & & \\
\hline Chloroform & 2.5 & 3.1 & 5.6 \\
Methanol & 60.0 & 68.7 & 61.8 \\
\hline
\end{tabular}

The extracts of S. mukorossi were tested for their toxicity against fungal pathogens by the Poisoned Food Technique ${ }^{[11]}$ on the basis of Inhibitory Concentration $\left(\mathrm{IC}_{50}\right)$.

Inhibitory Concentration (IC 50 )- The toxicity of extracts (chloroform and methanol) of the pericarp of $S$. mukorossi from different sources was determined against eight test fungi. A culture of the test fungi was grown on Potato Dextrose Agar (PDA) medium for certain period (generally 7 days) at the optimum temperature $\left(25^{\circ} \pm 1^{\circ} \mathrm{C}\right)$ for growth. Chloroform extract from all three sources was dissolved in acetone solvent to prepare the concentration (\%). Methanol extract from all three sources was dissolved in sterilized distilled water to make concentration (\%). The solvents used for dissolving were taken on the basis of polarity. 
PDA supplemented with different plant extracts at four concentrations $(0.5,1.0,1.5 \& 2.0 \%)$.

After solidification, small disc $(0.7 \mathrm{~cm}$ dia) of the fungus culture was cut with a sterile cork borer and transferred aseptically upside down at the center of a Petri-dish. Suitable checks were maintained where the culture discs were grown under the same conditions on PDA without extract. Solvent checks (a solvent which was used for dissolving extract i.e. acetone) were maintained to check out the inhibitory effect of solvent on fungi. Petri plates were incubated at $25^{\circ} \pm 1^{\circ} \mathrm{C}$. The radial growth of fungus colony was measured after every twenty-four hours till the fungus in the control plate completely occupied it. Three replications were maintained. The antifungal activity was evaluated by measuring the relative growth of fungus in treatment vis-a-vis control.

The percent growth inhibition over control was worked out using the formula of vincent ${ }^{[12]}$.

\section{$I(\%)=C-T / C \times 100$}

Where,

$\mathrm{I}(\%)=$ Growth Inhibition (\%)

$\mathrm{C}=$ Colony diameter in control $(\mathrm{mm})$

$\mathbf{T}=$ Colony diameter in treatment $(\mathrm{mm})$

\section{RESULTS}

Chloroform extract- In this study, Table 2 shows that irrespective of concentrations, maximum and significantly more antifungal activity was found in pericarp of seeds collected from Dehradun (37.8\%) against $A$. alternata and minimum inhibition was recorded in Nainatikker (31\%). The growth suppression of $A$. alternata significantly increased with changing concentrations of chloroform extract, for example, highest suppression was in case of $2 \%(44.5 \%)$ and lowest at $0.5 \%$ concentration (41\%) of chloroform extract, irrespective of seed sources.

Interactions between source and concentration $(S \times C)$ showed that Dehradun source was significantly better in terms of suppressing the growth of A. alternata than other two seed sources at all concentrations of chloroform extract (Table 2). Barring Nainatikker source, there was overlapping growth suppression of the pathogen in relation to concentration. For example, the growth inhibition of the fungus remained at par between the concentrations of 1.5 and $2 \%$ in both Dehradun (48.5 \& $49.3 \%$ respectively) and Gyarahdevi (42.8 \& 43.6\% respectively) sources.
The mycelial growth of $C$. gloeosporioides was suppressed maximum and significantly more in Dehradun source $40 \%$ shown in Table 2. However, Gyarahdevi (33\%) and Nainatikker (33.3\%) were at par, irrespective of concentrations. There was a significant increase of fungal growth inhibition over concentrations, irrespective of seed sources.

Following interactions between source and concentration $(\mathrm{S} \times \mathrm{C})$, it was observed that Dehradun source was significantly superior over the other two sources at all concentrations barring $0.5 \%$ (Table 2). Similarly, growth inhibition of $C$. gloeosporioides was significantly more at higher concentration of 1.5 (44.5\%) and 2.0 (52.7\%) in Gyarahdevi, however, it was significantly better at the lower concentration of 0.5 (37\%) and 1.0 (40\%) concentration in Nainatikker. There was a significant increase in growth suppression of the pathogen over-concentration in all the sources.

The growth inhibition of Phoma sp. was highest and significantly more in Nainatikker source $(72.0 \%)$ on the perusal of Table 2 \& Fig. 1. However, minimum inhibition was reported in Dehradun (50.9\%) irrespective of concentrations. There was a significant increase of fungal growth inhibition over concentrations, irrespective of seed sources. Interactions between source and concentration $(\mathrm{S} \times \mathrm{C})$ revealed that $100 \%$ inhibition of growth was exhibited by Nainatikker source starting from the lowest concentration of $0.5 \%$ (Table 2 \& Fig. 1 ). In the rest of the sources, there was linearity of significant fungal growth suppression over concentrations.

Irrespective of concentrations, Nainatikker (54.3\%) had the highest reduction of growth of $P$. dalbergiae whereas Dehradun (52.7\%) and Gyarahdevi (52.4\%) suppressed at par growth of the pathogen (Table 3 ). The growth suppression of fungus was significantly more over the concentrations, irrespective of seed sources.

Interactions between source and concentration (SxC) revealed that Nainatikker had significantly high growth inhibition of $P$. dalbergiae at the lowest concentration of $0.5 \%$ (61.9\%; Table 3). However, it had at par growth with Dehradun at the concentration of 1.0 (67.4 \& 66.2\%, respectively) and $2 \%$ (69.8 \& $70.1 \%$ respectively). Also, Nainatikker remained at par with both Dehradun and Gyarahdevi sources at the concentration of $1.5 \%$ (68.1, $67.5, \& 68.9 \%$, respectively). 
Table 2: Effect of different concentrations of chloroform extract of S. mukorossi on radial growth of test fungi

\begin{tabular}{|c|c|c|c|c|c|c|}
\hline \multirow{2}{*}{ Source } & \multicolumn{5}{|c|}{ Concentration (\%) / Inhibition (\%) } & \multirow{3}{*}{ Mean } \\
\hline & 0.0 & 0.5 & 1.0 & 1.5 & 2.0 & \\
\hline \multicolumn{6}{|c|}{ A. alternata } & \\
\hline Dehradun & $0.0(0.0)$ & $44.7\left(50.0^{*}\right)$ & $46.3(52.3)$ & $48.5(56.2)$ & $49.3(57.6)$ & $37.8(43.1)$ \\
\hline Gyarahdevi & $0.0(0.0)$ & $41.3(43.6)$ & $41.8(44.6)$ & $42.8(46.2)$ & $43.6(47.6)$ & $34(36.4)$ \\
\hline Nainatikker & $0.0(0.0)$ & $37.0(36.2)$ & $38.1(38.1)$ & $39.4(40.5)$ & $40.6(42.4)$ & $31(31.4)$ \\
\hline Mean & $0.0(0.0)$ & $41.0(43.1)$ & $42.1(45.0)$ & $43.6(47.6)$ & $44.5(49.1)$ & \\
\hline & Source (S) & \multicolumn{4}{|c|}{ Concentration (C) } & $\begin{array}{l}\text { Interaction } \\
\text { (SxC) }\end{array}$ \\
\hline SEM & 0.1 & \multicolumn{4}{|c|}{0.2} & 0.3 \\
\hline CD (5\%) & 0.4 & \multicolumn{4}{|c|}{0.5} & 0.8 \\
\hline \multicolumn{7}{|c|}{ C. gloeosporioides } \\
\hline Dehradun & $0.0(0.0)$ & $35.3(33.3)$ & $46.1(51.9)$ & $57.1(70.5)$ & $61.1(76.6)$ & $40(46.5)$ \\
\hline Gyarahdevi & $0.0(0.0)$ & $31.1(26.6)$ & $37.0(36.2)$ & $44.5(49.0)$ & $52.7(63.3)$ & $33(35.0)$ \\
\hline Nainatikker & $0.0(0.0)$ & $37.0(36.2)$ & $40.0(40.5)$ & $42.6(45.7)$ & $47.7(54.8)$ & $33.3(35.4)$ \\
\hline \multirow[t]{2}{*}{ Mean } & $0.0(0.0)$ & $34.4(32.0)$ & $40.8(42.8)$ & $48.0(55.0)$ & $53.9(64.9)$ & \\
\hline & Source (S) & \multicolumn{4}{|c|}{ Concentration (C) } & $\begin{array}{l}\text { Interaction } \\
\text { (SxC) }\end{array}$ \\
\hline SEM & 0.2 & \multicolumn{4}{|c|}{0.3} & 0.5 \\
\hline CD (5\%) & 0.6 & \multicolumn{4}{|c|}{0.8} & 1.4 \\
\hline
\end{tabular}

Phoma sp.

\begin{tabular}{ccccccc}
\hline Dehradun & $0.0(0.0)$ & $60.8(76.2)$ & $63.0(79.1)$ & $64.8(81.9)$ & $65.9(83.4)$ & $50.9(64.1)$ \\
Gyarahdevi & $0.0(0.0)$ & $58.3(72.3)$ & $63.1(79.5)$ & $65.2(82.4)$ & $69.8(88.1)$ & $51.3(64.5)$ \\
Nainatikker & $0.0(0.0)$ & $90.0(100)$ & $90.0(100)$ & $90.0(100)$ & $90.0(100)$ & $72(80.0)$ \\
Mean & $0.0(0.0)$ & $70.0(82.8)$ & $72.0(86.2)$ & $73.3(88.1)$ & $75.3(90.5)$ &
\end{tabular}

Source (S)

Concentration (C)

Interaction

(SxC)

0.10 .2

0.3

SEM

0.3

0.4

0.8 


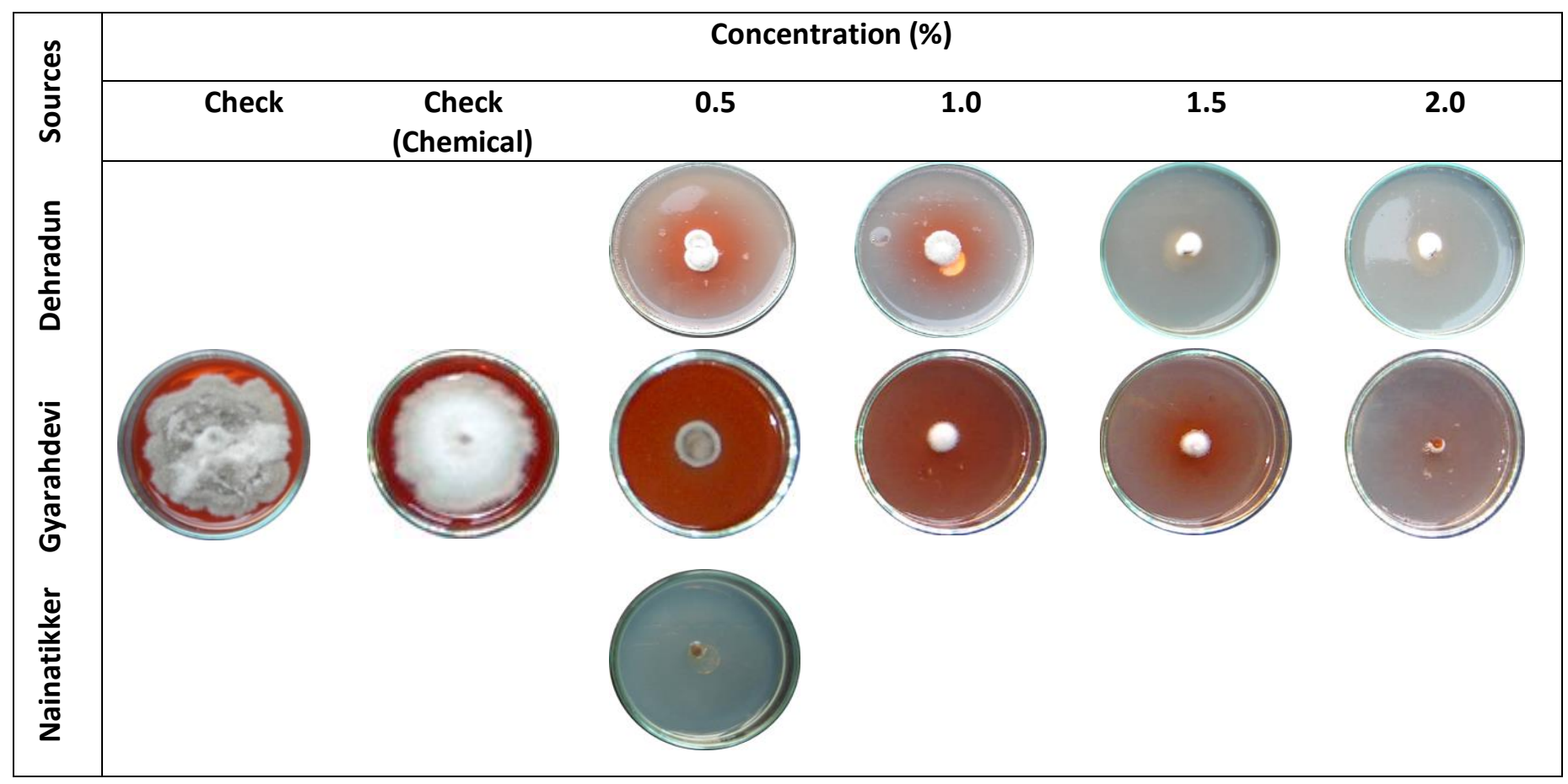

Fig. 1: Effect of chloroform extract of S. mukorossi from different sources on the growth of Phoma sp.

Irrespective of concentrations, maximum and significantly more antifungal activity was found in Dehradun source (33.0\%) followed by Gyarahdevi (31.6\%) and Nainatikker (29.2\%) against $F$. oxysporum (Table 3$)$. The fungus had significantly low inhibition percentage with an increase in the concentration of the chloroform extract i.e. minimum at $0.5 \%(34.2 \%)$ concentration and maximum at $2 \%$ $(42.8 \%)$, irrespective of seed sources.

Following interactions between source and concentration $(\mathrm{S} x \mathrm{C})$, Dehradun maintained its superiority excluding $1 \%$ where it remained at par with Gyarahdevi (39.8 \& 40\%) and 2\% with both Gyarahdevi and Nainatikker (43.4, 42.8 \& 42.3\%, respectively; Table 3). Also, the growth inhibition of $F$. oxysporum in Dehradun was at par with Gyarahdevi at $1 \%$ and with Gyarahdevi and Nainatikker sources at $2 \%$.
Irrespective of concentrations, Dehradun (52.1\%) had the highest reduction of growth of $G$. lucidum where as it was at par for Gyarahdevi (50.2\%) and Nainatikker (50.0\%) sources (Table 3 ). Irrespective of seed sources, growth suppression of $G$. lucidum increased significantly with rising concentrations.

Interactions between source and concentration (SxC), exhibited that Dehradun had $100 \%$ inhibition of $G$. lucidum at the concentration of $1.5 \%$ and above (Table 3). It was also observed that Gyarahdevi had significantly better growth reduction of the fungus at all the concentrations. Also, Dehradun suppressed at par growth at the lowest concentration of 0.5 (60\%) and $1 \%$ (60.8\%). The fungal growth inhibition at all the sources significantly increased over concentrations.

Table 3: Effect of different concentrations of chloroform extract of S. mukorossi on radial growth of test fungi

Concentration (\%) / Inhibition (\%)

Source

\begin{tabular}{lllll}
\hline 0.0 & 0.5 & 1.0 & 1.5 & 2.0 \\
\hline
\end{tabular}

\section{P. dalbergiae}

$\begin{array}{lllllll}\text { Dehradun } & 0.0(0.0) & 60.0\left(74.3^{*}\right) & 66.2(83.7) & 67.5(85.3) & 70.1(88.3) & 52.7(66.4) \\ \text { Gyarahdevi } & 0.0(0.0) & 60.0(74.8) & 62.1(78.1) & 68.9(86.7) & 71.3(89.7) & 52.4(65.9)\end{array}$




$\begin{array}{ccccccc}\text { Nainatikker } & 0.0(0.0) & 66.3(83.8) & 67.4(85.2) & 68.1(86.2) & 69.8(88.1) & 54.4(68.7) \\ \text { Mean } & 0.0(0.0) & 61.9(77.7) & 65.2(82.7) & 68.1(86.1) & 70.4(88.7)\end{array}$

\begin{tabular}{cccc}
\hline & Source (S) & Concentration (C) & $\begin{array}{c}\text { Interaction } \\
\text { (SxC) }\end{array}$ \\
\cline { 2 - 4 } SEM & 0.2 & 0.3 & 0.5 \\
CD (5\%) & 0.6 & 0.8 & 1.4 \\
\hline
\end{tabular}

\begin{tabular}{ccccccc}
\hline Dehradun & $0.0(0.0)$ & $38.4(38.6)$ & $39.8(41.0)$ & $43.1(46.7)$ & $43.4(47.1)$ & $33(34.7)$ \\
Gyarahdevi & $0.0(0.0)$ & $34.4(31.9)$ & $40.0(40.5)$ & $41.5(43.8)$ & $42.8(46.2)$ & $31.6(32.5)$ \\
Nainatikker & $0.0(0.0)$ & $30.0(24.8)$ & $34.4(31.9)$ & $40.0(40.5)$ & $42.3(45.2)$ & $29.2(28.5)$ \\
Mean & $0.0(0.0)$ & $34.2(31.8)$ & $38.0(37.8)$ & $41.3(43.7)$ & $42.8(46.2)$ & \\
\hline
\end{tabular}

Source (S)
Concentration (C)
Interaction

(SxC)

\begin{tabular}{|c|c|c|c|c|c|c|}
\hline SEM & 0.2 & \multicolumn{4}{|c|}{0.3} & 0.5 \\
\hline CD (5\%) & 0.6 & \multicolumn{4}{|c|}{0.8} & 1.3 \\
\hline \multicolumn{7}{|c|}{ G. lucidum } \\
\hline Dehradun & $0.0(0.0)$ & $36.0(33.8)$ & 44.7(49.5) & $90.0(100)$ & $90.0(100)$ & $52.1(56.7)$ \\
\hline Gyarahdevi & $0.0(0.0)$ & $60.0(74.8)$ & $60.8(76.2)$ & $64.1(80.9)$ & $66.1(83.6)$ & $50.2(63.1)$ \\
\hline Nainatikker & $0.0(0.0)$ & $45.3(50.5)$ & $49.4(58.0)$ & $53.0(63.8)$ & $57.1(70.5)$ & $50(48.6)$ \\
\hline Mean & $0.0(0.0)$ & $47.0(53.0)$ & $51.6(61.2)$ & $69.0(81.6)$ & 71.1(84.7) & \\
\hline & Source (S) & \multicolumn{4}{|c|}{ Concentration (C) } & $\begin{array}{l}\text { Interaction } \\
\text { (SxC) }\end{array}$ \\
\hline SEM & 0.1 & \multicolumn{4}{|c|}{0.2} & 0.3 \\
\hline CD (5\%) & 0.4 & \multicolumn{4}{|c|}{0.5} & 0.9 \\
\hline
\end{tabular}

*Values in parentheses are original

Irrespective of concentrations, Nainatikker (45.7\%) had significant and more growth suppression against $R$. solani and lowest in Dehradun 41.3\% shown in Table 3 \& Fig. 2. Irrespective of seed sources, $R$. solani showed a linear and significant relationship between concentrations of extract and growth inhibition.

Interactions between source and concentration ( $\mathrm{S} \times \mathrm{C}$, ) revealed that Nainatikker had suppressed the growth of test fungus to the maximum extent that was significantly more than other sources at all concentrations (Table 4 \& Fig. 2). Moreover, Dehradun and Gyarahdevi suppressed at par growth of $R$. solani at the lowest concentration of
0.5 (48.8 \& 48.5\% respectively) and at 1.0 (51.3 \& 50.6\%, respectively), whereas, Gyarahdevi was significantly better than Dehradun at the higher concentration of 1.5 (53.9 vs $52.2 \%$ ) and $2 \%$ ( 57.1 vs $54.4 \%$ ). It was also recorded that all the sources suppressed the growth of $R$. solani significantly over changing concentrations.

It was observed in Table 4 and Fig. 3 that Nainatikker (47.1\%) registered significantly more and Dehradun (37.2\%) had the lowest antifungal activity against $T$. piluliferum irrespective of concentrations. The growth reduction of $T$. piluliferum increased significantly with rising concentrations, irrespective of seed sources. 
Pursuing the interactions between source and concentration $(\mathrm{S} x \mathrm{C})$, it was observed that Nainatikker had significant and maximum inhibition of growth at the higher concentrations of 1.5 (60.2\%) and 2\% (64.1\%) than other two sources (Table 4 \& Fig. 3) However,
Gyarahdevi performed significantly better than Dehradun at all the concentrations tested. It was also recorded that in all three sources fungal growth suppression increased significantly at the higher concentrations of $1.5 \%$ and $2 \%$.

Table 4: Effect of different concentrations of chloroform extract of S. mukorossi on radial growth of test fungi

\begin{tabular}{|c|c|c|c|c|c|c|}
\hline \multirow{3}{*}{ Source } & \multicolumn{5}{|c|}{ Concentration (\%)/Inhibition (\%) } & \multirow{3}{*}{ Mean } \\
\hline & 0.0 & 0.5 & 1.0 & 1.5 & 2.0 & \\
\hline & \multicolumn{5}{|c|}{ R. solani } & \\
\hline Dehradun & $0.0(0.0)$ & $48.8\left(56.7^{*}\right)$ & $51.3(60.9)$ & $52.2(62.4)$ & $54.4(66.6)$ & $41.3(49.3)$ \\
\hline Gyarahdevi & $0.0(0.0)$ & $48.5(56.2)$ & $50.6(59.7)$ & $53.9(65.2)$ & $57.1(70.5)$ & $42(50.3)$ \\
\hline Nainatikker & $0.0(0.0)$ & $54.7(66.6)$ & $56.5(69.5)$ & $57.4(70.9)$ & $60.0(74.8)$ & $45.7(56.4)$ \\
\hline \multirow[t]{2}{*}{ Mean } & $0.0(0.0)$ & $50.7(59.8)$ & $52.8(63.4)$ & $54.5(66.2)$ & $57.1(70.6)$ & \\
\hline & Source (S) & \multicolumn{4}{|c|}{ Concentration (C) } & $\begin{array}{l}\text { Interaction } \\
\text { (SxC) }\end{array}$ \\
\hline SEM & 0.1 & \multicolumn{4}{|c|}{0.2} & 0.3 \\
\hline $\mathrm{CD}(5 \%)$ & 0.4 & \multicolumn{4}{|c|}{0.5} & 0.8 \\
\hline \multicolumn{7}{|c|}{ T. piluliferum } \\
\hline Dehradun & $0.0(0.0)$ & $42.5(45.7)$ & 43.1(46.6) & $45.8(51.4)$ & $54.7(66.6)$ & $37.2(42.1)$ \\
\hline Gyarahdevi & $0.0(0.0)$ & $53.9(65.2)$ & $56.8(69.7)$ & $57.4(71.3)$ & $60.8(76.2)$ & $45.8(56.5)$ \\
\hline Nainatikker & $0.0(0.0)$ & $54.7(66.7)$ & $56.5(69.5)$ & $60.2(75.3)$ & $64.1(80.9)$ & $47.1(58.5)$ \\
\hline \multirow[t]{2}{*}{ Mean } & $0.0(0.0)$ & $50.4(59.2)$ & $52.1(62.0)$ & $54.5(65.9)$ & $60.0(74.6)$ & \\
\hline & Source (S) & \multicolumn{4}{|c|}{ Concentration (C) } & $\begin{array}{c}\text { Interaction } \\
(\mathrm{SxC})\end{array}$ \\
\hline SEM & 0.2 & \multicolumn{4}{|c|}{0.3} & 0.5 \\
\hline CD (5\%) & 0.6 & \multicolumn{4}{|c|}{0.7} & 1.3 \\
\hline
\end{tabular}

*Values in parentheses are original 


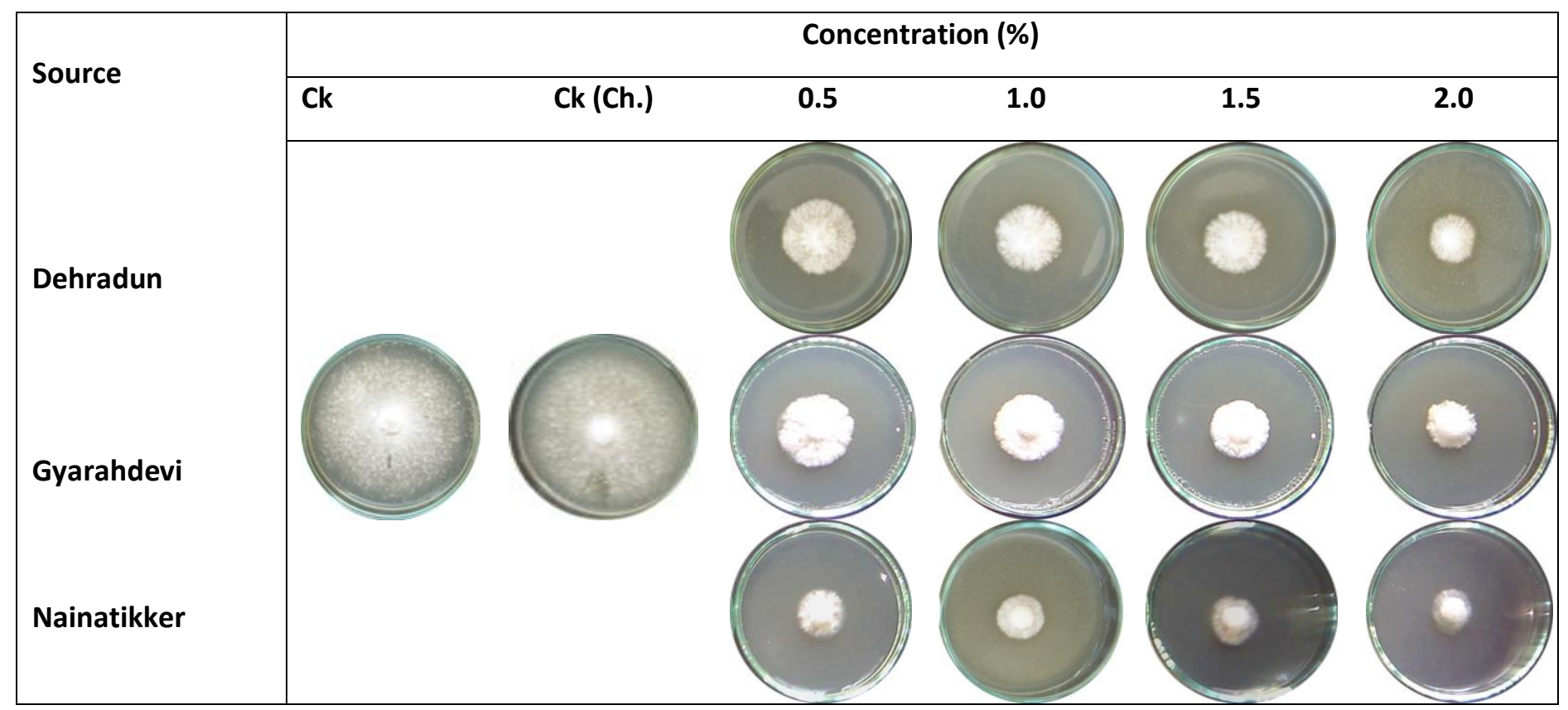

Ck= Check (Fungal culture media), Ch.= Check chemical control (Media containing chloroform)

Fig. 2: Effect of chloroform extract of S. mukorossi from different sources on the growth of $R$. solani

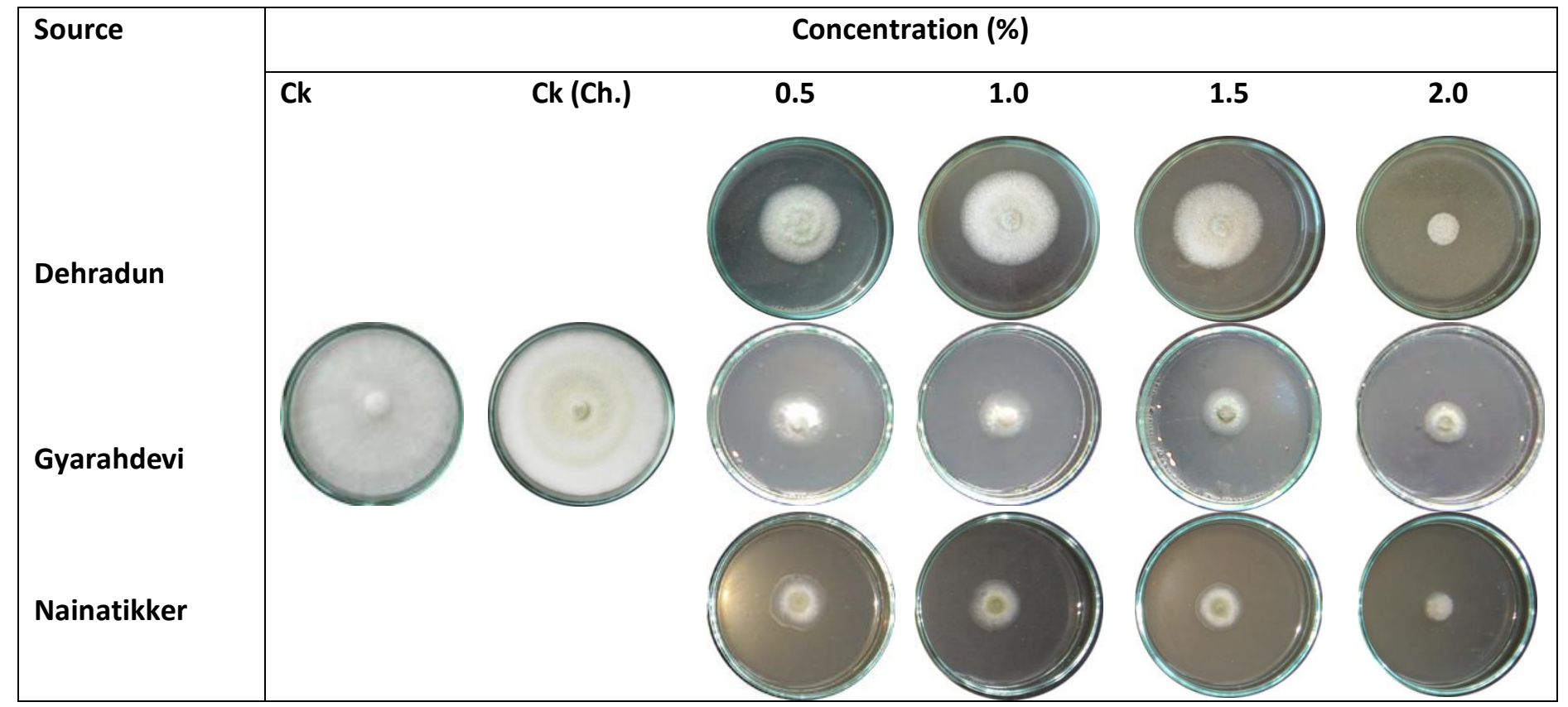

Ck= Check (Fungal culture media), Ch.= Check chemical control (Media containing chloroform)

Fig. 3: Effect of chloroform extract of S. mukorossi from different sources on the growth of T. piluliferum

Methanol extract- Table 5 revealed that irrespective of concentrations, maximum and significantly more antifungal activity was found in the pericarp of seeds collected from Dehradun (33.8\%) against $A$. alternata followed by Gyarahdevi (31.1\%) and Nainatikker (30.1\%). Irrespective of seed sources, all the concentrations of methanol extract showed significant and increasing suppression of growth i.e. maximum at concentration of $2 \%(42.4 \%)$ and minimum at $0.5 \%(36.8 \%)$.
Interactions between source and concentration (SxC) reveals that Dehradun was significantly better in suppressing the growth of $A$. alternata than other two seed sources at all concentrations except $2 \%$ of methanol extract where it remained at par with Gyarahdevi (Table 5), while Gyarahdevi had significantly more growth reduction in respect to Nainatikker at a higher concentration of $1.5 \%$ (40.4 \& 38.4\%) and $2 \%$ (43.7 \& 40.1\%). Only Gyarahdevi had significant 
suppression of Alternaria growth over concentrations while in rest of the two sources there were overlapping trends.

Irrespective of concentrations, Nainatikker (34.6\%) and Dehradun (34.1\%) had at par reduction of growth of $C$. gloeosporioides (Table 5). Irrespective of seed sources, growth suppression of $C$. gloeosporioides showed linearity over concentrations.

Interactions between source and concentration (SxC) showed that Dehradun and Nainatikker suppressed at par growth at all the concentrations of methanol extract (Table 5). Also, both of these sources remained at par with Gyarahdevi at the higher concentration of $1.5 \%$.
The growth inhibition of Phoma sp. was significantly more in Gyarahdevi (68.1\%) and lowest in Dehradun (52.7\%) irrespective of concentrations (Table 5 \& Fig. 4). It was also found, that growth inhibition from 1 to $2 \%$ was at par all the concentrations against Phoma sp., irrespective of sources.

Interactions between source and concentration (SxC) revealed that mycelial growth of Phoma sp. completely reduced to $100 \%$ from 1.0 concentration in Gyarahdevi and Nainatikker sources (Table 5 \& Fig. 4). While Dehradun had minimum inhibition of the fungus with overlapping trends over concentrations.

Table 5: Effect of different concentrations of methanol extract of S. mukorossi on radial growth of test fungi

\begin{tabular}{|c|c|c|c|c|c|c|}
\hline \multirow{2}{*}{ Source } & \multicolumn{5}{|c|}{ Concentration (\%) / Inhibition (\%) } & \multirow{2}{*}{ Mean } \\
\hline & 0.0 & 0.5 & 1.0 & 1.5 & 2.0 & \\
\hline \multicolumn{7}{|c|}{ A. alternata } \\
\hline Dehradun & $0.0(0.0)$ & $40.3(41.9 *)$ & $42.0(44.6)$ & $42.8(46.2)$ & $43.6(47.6)$ & $33.8(36.1)$ \\
\hline Gyarahdevi & $0.0(0.0)$ & $34.4(31.9)$ & $37.3(36.6)$ & $40.4(41.9)$ & $43.7(47.1)$ & $31.1(31.5)$ \\
\hline Nainatikker & $0.0(0.0)$ & $35.8(34.2)$ & $36.4(35.2)$ & $38.4(38.5)$ & $40.1(41.4)$ & $30.1(29.9)$ \\
\hline \multirow[t]{2}{*}{ Mean } & $0.0(0.0)$ & $36.8(36.0)$ & $38.5(39.5)$ & $40.5(42.2)$ & $42.4(45.4)$ & \\
\hline & Source (S) & \multicolumn{4}{|c|}{ Concentration (C) } & $\begin{array}{l}\text { Interaction } \\
\text { (SxC) }\end{array}$ \\
\hline SEM & 0.3 & \multicolumn{4}{|c|}{0.3} & 0.6 \\
\hline CD (5\%) & 0.8 & \multicolumn{4}{|c|}{1.0} & 1.7 \\
\hline
\end{tabular}

C. gloeosporioides

\begin{tabular}{ccccccc}
\hline Dehradun & $0.0(0.0)$ & $40.3(41.9)$ & $42.6(45.7)$ & $43.1(46.7)$ & $44.7(49.5)$ & $34.1(36.8)$ \\
Gyarahdevi & $0.0(0.0)$ & $35.5(33.8)$ & $38.7(39.0)$ & $43.6(47.6)$ & $46.9(53.3)$ & $32.9(34.8)$ \\
Nainatikker & $0.0(0.0)$ & $40.3(41.9)$ & $42.5(45.7)$ & $44.2(48.5)$ & $45.8(51.4)$ & $34.6(37.5)$ \\
Mean & $0.0(0.0)$ & $38.7(39.2)$ & $41.3(43.5)$ & $43.6(47.6)$ & $45.8(51.4)$ & \\
\hline \multirow{2}{*}{ SEM } & Source (S) & \multicolumn{2}{c}{ Concentration (C) } & $\begin{array}{c}\text { Interaction } \\
\text { (SxC) }\end{array}$ \\
\cline { 2 - 6 } CD (5\%) & 0.3 & 0.3 & 0.6 \\
\hline
\end{tabular}

Phoma sp.

\begin{tabular}{cllllll}
\hline Dehradun & $0.0(0.0)$ & $64.8(81.9)$ & $65.2(82.4)$ & $66.3(83.8)$ & $67.0(84.8)$ & $52.7(66.6)$ \\
Gyarahdevi & $0.0(0.0)$ & $70.7(89.1)$ & $90.0(100)$ & $90.0(100)$ & $90.0(100)$ & $68.1(77.8)$ \\
Nainatikker & $0.0(0.0)$ & $66.3(83.8)$ & $90.0(100)$ & $90.0(100)$ & $90.0(100)$ & $67.3(76.8)$ \\
Mean & $0.0(0.0)$ & $67.3(84.9)$ & $81.7(94.1)$ & $82.1(94.6)$ & $82.3(94.9)$ & \\
\hline
\end{tabular}




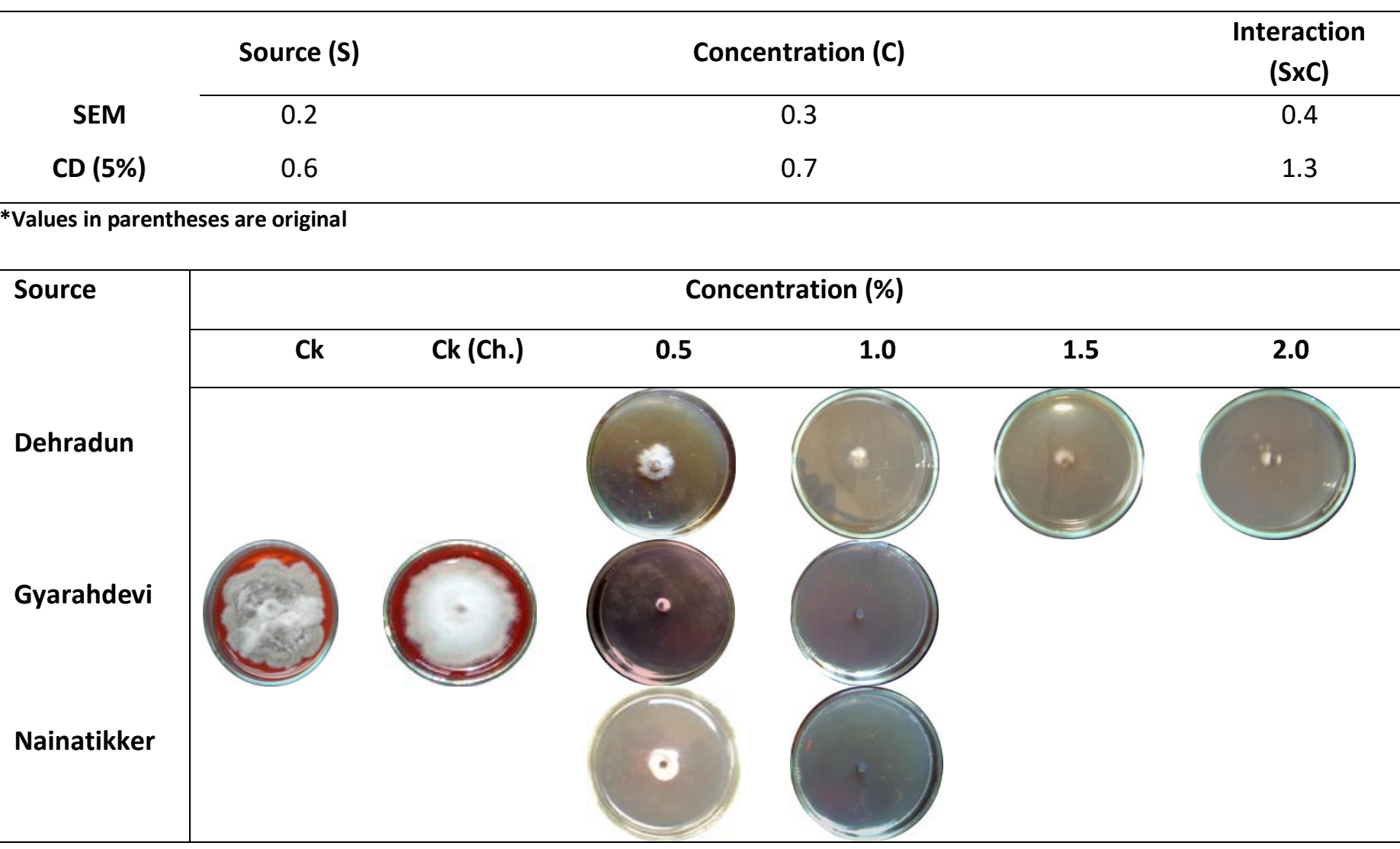

Fig. 4: Effect of methanol extract of S. mukorossi from different sources on the growth of Phoma sp.

Irrespective of concentrations, Gyarahdevi had maximum and significantly higher growth inhibition of $68.2 \%$, while Dehradun had lowest of $55.6 \%$ against $P$. dalbergiae (Table 6). Irrespective of sources, suppression of mycelial growth of $P$. dalbergiae was at par at $1 \%$ and $1.5 \%$ concentration.

Following interactions between source and concentration $(\mathrm{S} x \mathrm{C})$, it was concluded that Gyarahdevi had $100 \%$ antifungal activity at the concentration of 1.0 against $P$. dalbergiae (Table 6 ). Barring the concentration of 1.0, Nainatikker was at par with Dehradun at 0.5, 1.5 and 2.0 concentrations. Also, Dehradun and Nainatikker were at par at the lower concentrations of 0.5 and 1.0 and at the higher of 1.5 and 2.0.

It was observed in Table 6 that Gyarahdevi (33.7\%) registered significantly more and Dehradun (27.7\%) had the lowest antifungal activity against $F$. oxysporum, irrespective of concentrations. The growth reduction of the fungus increased significantly with rising concentrations, irrespective of seed sources.

Interactions between source and concentration (SxC) revealed that Gyarahdevi had significantly better growth suppression at all concentrations (Table 6). Also, it remained at par with Nainatikker at the highest concentration of $2 \%$ ( $43.6 \& 42.6 \%$ ).
Moreover, Nainatikker was second to highest and was at par at the concentration of 1.0 and 1.5 .

Table 6 showed significantly differential growth suppression of $G$. lucidum by pericarp of seeds collected from different sources, for example, Nainatikker had highest (45.0\%) and Dehradun had lowest of $37.3 \%$, irrespective of concentrations. G. lucidum showed a linear and significant relationship between concentrations of extract and growth inhibition, irrespective of sources. Interactions between source and concentration $(\mathrm{S} x \mathrm{C})$ revealed that Nainatikker had highest growth suppression of $G$. Iucidum at all the concentrations barring $2 \%$ concentration of Dehradun source, where $61.7 \%$ of growth inhibition was observed (Table 6). At lower concentrations, up to 1.5 Gyarahdevi performed better than Dehradun while at higher concentration of $1.5 \%$ and $2 \%$ Dehradun scored significantly better than Gyarahdevi. The antifungal activity of Gyarahdevi had overlapping trends over concentrations, while the rest of the two recorded significant suppression with increasing concentrations. 
Table 6: Effect of different concentrations of methanol extract of S. mukorossi on radial growth of test fungi

\begin{tabular}{|c|c|c|c|c|c|c|}
\hline \multirow{3}{*}{ Source } & \multicolumn{5}{|c|}{ Concentration (\%) / Inhibition (\%) } & \multirow{3}{*}{ Mean } \\
\hline & 0.0 & 0.5 & 1.0 & 1.5 & 2.0 & \\
\hline & \multicolumn{5}{|c|}{ P. dalbergiae } & \\
\hline Dehradun & $0.0(0.0)$ & $68.2\left(86.2^{*}\right)$ & $69.0(87.1)$ & $69.8(88.1)$ & $70.7(89.0)$ & $55.6(70.1)$ \\
\hline Gyarahdevi & $0.0(0.0)$ & $71.1(89.5)$ & $90.0(100)$ & $90.0(100)$ & $90.0(100)$ & $68.2(77.9)$ \\
\hline Nainatikker & $0.0(0.0)$ & $69.4(87.6)$ & $69.8(88.1)$ & $70.7(89.0)$ & $71.6(90.0)$ & $56.3(71.0)$ \\
\hline \multirow[t]{2}{*}{ Mean } & $0.0(0.0)$ & $70.0(87.8)$ & 76.3(91.7) & 76.8(92.4) & 77.4(93.0) & \\
\hline & Source (S) & \multicolumn{4}{|c|}{ Concentration (C) } & $\begin{array}{l}\text { Interaction } \\
(\mathrm{SxC})\end{array}$ \\
\hline SEM & 0.2 & \multicolumn{4}{|c|}{0.3} & 0.4 \\
\hline $\mathrm{CD}(\mathbf{5 \% )}$ & 0.6 & \multicolumn{4}{|c|}{0.7} & 1.2 \\
\hline \multicolumn{7}{|c|}{ F. oxysporum } \\
\hline Dehradun & $0.0(0.0)$ & $31.7(27.6)$ & $33.5(30.5)$ & $34.7(32.4)$ & $38.7(39.0)$ & $27.7(25.9)$ \\
\hline Gyarahdevi & $0.0(0.0)$ & $40.3(41.9)$ & $41.5(43.8)$ & $42.8(46.2)$ & $43.6(47.6)$ & $33.7(35.9)$ \\
\hline Nainatikker & $0.0(0.0)$ & $37.0(35.7)$ & $40.1(41.4)$ & $40.6(42.4)$ & $42.6(45.7)$ & $32(33.1)$ \\
\hline \multirow[t]{2}{*}{ Mean } & $0.0(0.0)$ & $36.3(35.1)$ & $38.3(38.6)$ & $39.4(40.3)$ & $41.6(44.1)$ & \\
\hline & Source (S) & \multicolumn{4}{|c|}{ Concentration (C) } & $\begin{array}{l}\text { Interaction } \\
\text { (SxC) }\end{array}$ \\
\hline SEM & 0.2 & \multicolumn{4}{|c|}{0.2} & 0.4 \\
\hline $\mathrm{CD}(5 \%)$ & 0.5 & \multicolumn{4}{|c|}{0.6} & 1.0 \\
\hline \multicolumn{7}{|c|}{ G. lucidum } \\
\hline Dehradun & $0.0(0.0)$ & $32.6(29.0)$ & $35.6(33.8)$ & $56.4(69.3)$ & $61.7(77.6)$ & $37.3(42.0)$ \\
\hline Gyarahdevi & $0.0(0.0)$ & $50.8(60.1)$ & $51.3(60.9)$ & $52.7(63.3)$ & $53.6(64.7$ & 41.7(49.8) \\
\hline Nainatikker & $0.0(0.0)$ & $52.4(62.9)$ & $55.1(67.3)$ & $57.7(71.4)$ & $60.0(74.3)$ & $45(55.2)$ \\
\hline \multirow[t]{2}{*}{ Mean } & $0.0(0.0)$ & $45.3(50.7)$ & 47.3(54.0) & $55.6(68.0)$ & $58.3(72.2)$ & \\
\hline & Source (S) & \multicolumn{4}{|c|}{ Concentration (C) } & $\begin{array}{l}\text { Interaction } \\
\text { (SxC) }\end{array}$ \\
\hline SEM & 0.2 & \multicolumn{4}{|c|}{0.2} & 0.4 \\
\hline CD (5\%) & 0.5 & \multicolumn{4}{|c|}{0.6} & 1.1 \\
\hline
\end{tabular}

*Values in parentheses are original

Irrespective of concentrations, Nainatikker had maximum and significantly more growth reduction of $48 \%$ followed by Dehradun (44.8\%) and Gyarahdevi $(41.6 \%$, Table $7 \&$ Fig. 5$)$ sources against $R$. solani. All the concentrations had a linear and significant reduction of growth of $R$. solani, irrespective of sources.
Interactions between source and concentration (SxC) revealed that Nainatikker had significantly better growth suppression at all concentrations followed by Dehradun and Gyarahdevi sources (Table 7 \& Fig. 5). It was also recorded that Gyarahdevi and Nainatikker had overlapping trends among concentrations. 
Irrespective of concentrations, Gyarahdevi had significant and maximum inhibition of $50 \%$ of $T$. piluliferum followed by Nainatikker (46.0\%) and Dehradun (44.9\%; Table 7 \& Fig.6) sources. Irrespective of sources, $T$. piluliferum had significant and linear growth reduction over concentrations.

Interactions between source and concentration (SxC), showed that the performance of Gyarahdevi was significantly better than other two sources and at all the concentrations and Nainatikker and Dehradun had at par growth of $T$. piluliferum at all concentrations barring $2 \%$ where Nainatikker performed significantly better than Dehradun (Table 7 \& Fig. 6) Barring the concentration of 2.0, all the sources had overlapping trends among concentrations.

Table 7: Effect of different concentrations of methanol extract of S. mukorossi on radial growth of test fungi

\begin{tabular}{|c|c|c|c|c|c|c|}
\hline \multirow{3}{*}{ Source } & \multicolumn{5}{|c|}{ Concentration (\%) / Inhibition (\%) } & \multirow[t]{3}{*}{ Mean } \\
\hline & 0.0 & 0.5 & 1.0 & 1.5 & 2.0 & \\
\hline & \multicolumn{5}{|c|}{ R. solani } & \\
\hline Dehradun & $0.0(0.0)$ & $54.0(64.8)^{*}$ & $55.4(67.6)$ & $57.1(70.5)$ & $58.0(71.9)$ & $44.8(54.9)$ \\
\hline Gyarahdevi & $0.0(0.0)$ & $50.8(60.0)$ & $51.6(61.4)$ & $52.4(62.8)$ & $53.4(64.3)$ & $41.6(49.7)$ \\
\hline Nainatikker & $0.0(0.0)$ & $57.7(71.4)$ & $60.0(74.3)$ & $60.2(75.2)$ & $62.0(78.1)$ & $48(59.8)$ \\
\hline \multirow[t]{2}{*}{ Mean } & $0.0(0.0)$ & $54.0(65.4)$ & $56.0(67.7)$ & $57.0(69.5)$ & $57.8(71.4)$ & \\
\hline & Source (S) & \multicolumn{4}{|c|}{ Concentration (C) } & $\begin{array}{l}\text { Interaction } \\
\text { (SxC) }\end{array}$ \\
\hline SEM & 0.2 & \multicolumn{4}{|c|}{0.3} & 0.6 \\
\hline $\mathrm{CD}(5 \%)$ & 0.7 & \multicolumn{4}{|c|}{0.9} & 1.6 \\
\hline \multicolumn{7}{|c|}{ T. piluliferum } \\
\hline Dehradun & $0.0(0.0)$ & $54.0(64.7)$ & $55.3(67.6)$ & $57.1(70.5)$ & $58.3(72.3)$ & $44.9(55.0)$ \\
\hline Gyarahdevi & $0.0(0.0)$ & $60.5(75.7)$ & $61.4(77.1)$ & $62.4(78.6)$ & $63.4(80.0)$ & $50.0(62.3)$ \\
\hline Nainatikker & $0.0(0.0)$ & $55.1(67.3)$ & $56.0(68.7)$ & $57.0(70.1)$ & $60.0(74.3)$ & $46.0(56.1)$ \\
\hline \multirow[t]{2}{*}{ Mean } & $0.0(0.0)$ & $56.4(69.2)$ & $57.6(71.1)$ & $58.8(73.0)$ & $60.4(75.6)$ & \\
\hline & Source (S) & \multicolumn{4}{|c|}{ Concentration (C) } & $\begin{array}{l}\text { Interaction } \\
(\mathrm{SxC})\end{array}$ \\
\hline SEM & 0.2 & \multicolumn{4}{|c|}{0.3} & 0.5 \\
\hline $\mathrm{CD}(5 \%)$ & 0.7 & \multicolumn{4}{|c|}{0.9} & 1.5 \\
\hline
\end{tabular}




\begin{tabular}{|c|c|c|c|c|c|c|}
\hline Source & & & & (\%) & & \\
\hline & Ck & Ck (Ch.) & 0.5 & 1.0 & 1.5 & 2.0 \\
\hline Dehradun & & & & & 3 & 0 \\
\hline Gyarahdevi & & & & & & \\
\hline Nainatikker & & & & & 0 & e \\
\hline
\end{tabular}

Fig. 5: Effect of methanol extract of S. mukorossi from different sources on the growth of $R$. solani

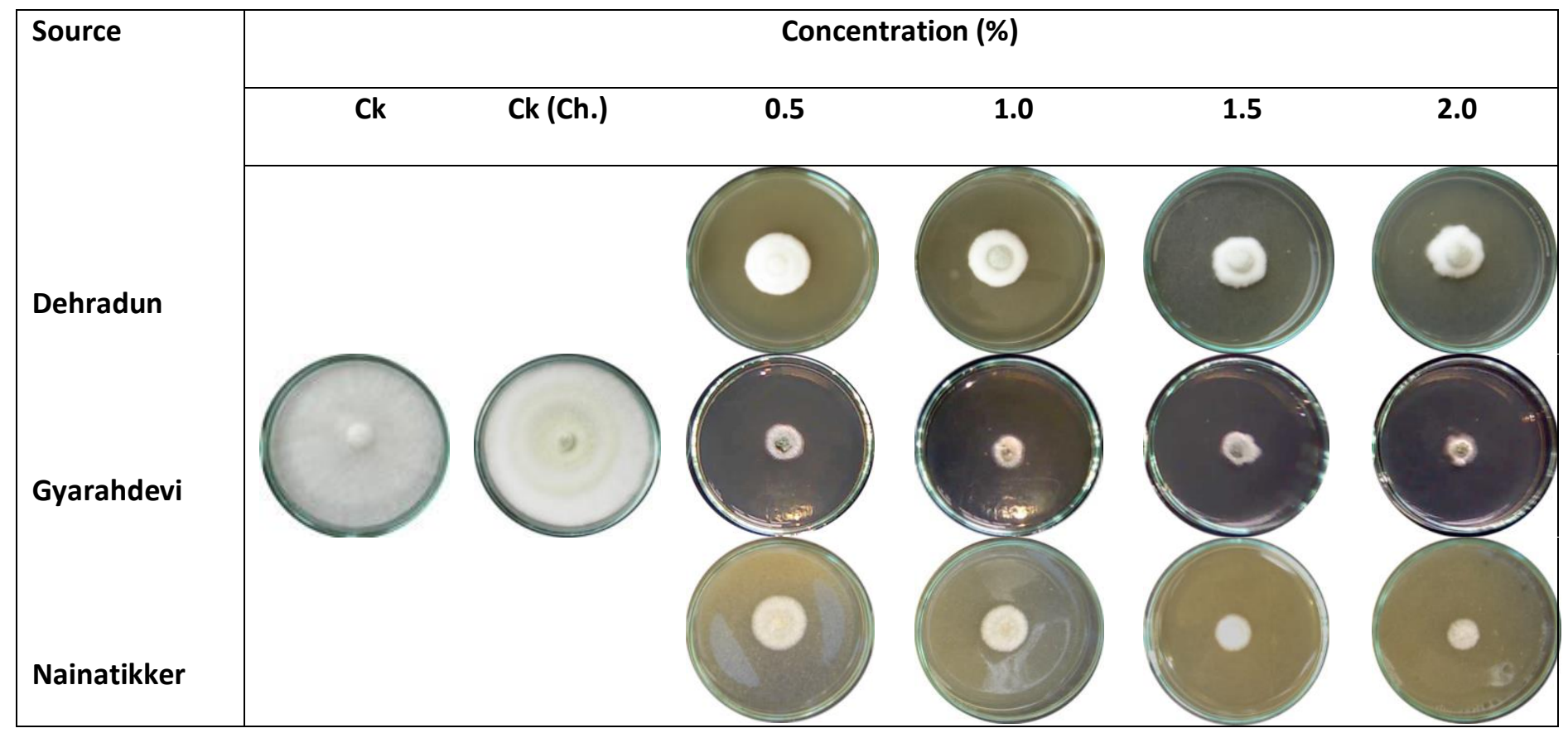

Fig. 6: Effect of methanol extract of S. mukorossi from different sources on the growth of T. piluliferum

\section{DISCUSSION}

Phytochemical constituents in the plant samples are known to be biologically active compounds and they are responsible for different activities such as antioxidant, antimicrobial, antifungal, and anticancer [13,14]. Regarding chloroform extract, the current study found that this extract of all the three sources presented $I_{50}$ at all concentrations against only two fungi namely, Phoma sp. and $P$. dalbergiae. Similar to the present study, ethanol and chloroform extracts of $S$. mukorossi had shown antibacterial activity against $H$. pylori ${ }^{[8]}$ at very low concentrations ( $10 \mu \mathrm{g} / \mathrm{ml}$ for both extracts). In a subsequent study, Tsuzuki verified that the crude extracts (hydroalcoholic and butanol) of S. saponaria showed strong antifungal activity against clinical isolates of yeasts $C$. albicans ${ }^{[15]}$. Focusing on methanol extract, we had observed that this extract of all the three sources has attained $\mathrm{IC}_{50}$ at all concentrations against four fungi namely, Phoma sp., P. dalbergiae, $R$. solani and $T$. piluliferum. Previous studies had reported that ethyl acetate extract from endophytes of $S$. Saponaria showed a greater antimicrobial activity against some pathogenic 
bacteria but methanol extract did not show positive results for human pathogenic bacteria ${ }^{[16]}$. Results concluded that the methanol extract of different sources performed much better than chloroform extract barring one fungus, G. lucidum (1.5\%); all other fungi exhibited $\mathrm{IC}_{50}$ at their minimum concentration of $0.5 \%$. Predominantly, antifungal activity of pericarp extracts (chloroform and methanol) of S. mukorossi was never tested against forest fungi though it was a popular tree under intensive uses.

\section{CONCLUSIONS}

The results of preliminary screening suggested that chloroform extract of all three sources could not achieve $\mathrm{IC}_{50}$ against $A$. alternata and $F$. oxysporum ranging from $0.5 \%$ to $2 \%$ concentration. Further, it was common between both extracts of all three sources registered $\mathrm{IC}_{50}$ at all concentrations against Phoma sp. and $P$. dalbergiae.

Future studies concerning antimicrobial activities must be carried out with other extracts (petroleum ether, butanol etc.) of fruit pericarp of S. mukorossi against forest fungi to justify their antifungal properties.

\section{ACKNOWLEDGMENTS}

The authors were thankful to the research fellows and other staff for providing support during the course of the investigation. We were also thankful to Director FRI for providing all the necessary facilities required for the successful completion of the work.

\section{CONTRIBUTION OF AUTHORS}

Research concept- Dr. Y. P. Singh, Dr. Vineet Kumar

Research design- Dr. Y. P. Singh, Dr. Prerana Badoni

Supervision- Dr. Y. P. Singh, Dr. Vineet Kumar

Materials- Dr. Prerana Badoni

Data collection- Dr. Prerana Badoni

Data analysis and interpretation- Dr. Prerana Badoni, Dr. Y. P. Singh

Literature search- Dr. Prerana Badoni

Writing article- Dr. Prerana Badoni, Dr. Kartik Uniyal

Critical review- Dr. Y. P. Singh

Article editing- Dr. Prerana Badoni, Dr. Kartik Uniyal

Final approval- Dr. Y. P. Singh

\section{REFERENCES}

[1] Kawsar SMA, Uddin, MS, Huq E, Nahar N, Ozeki Y. Biological investigation of Macrotyloma uniflorum
Linn. extracts against some pathogens. J. Biol. Sci., 2008; 8: 1051-56.

[2] Singh RP, Jain DA. Evaluation of antimicrobial activity of alcoholic and aqueous extracts of five plants used in traditional medicine in north India. Int. J. Pharm. Tech. Res., 2011; 3(1): 376-80.

[3] Khanam Z, Wen CS, Bhat IUH. Phytochemical screening and antimicrobial activity of root and stem extracts of wild Eurycoma longifolia Jack (Tongkat Ali). J. King Saud University-Sci., 2015; 27: 23-30.

[4] Dubey NK, Shukla R, Kumar A, Singh P and Prakash B. Prospects of botanical pesticides in sustainable agriculture. Curr. Sci., 2010; 98(4): 479-80.

[5] Gedeon J. Saponins from Indian soapnuts. J. Sci. Ind. Res., 1954; 13B: 427-28.

[6] Osbourn AE. Saponins and plant defence- A soap story. Trends Plant Sci., 1996; 1: 4-9.

[7] Ojha P, Maikhuri JP, Gupta G. Effect of spermicides on Lactobacillus acidophilus in vitro nonoxynol-9 vs. Sapindus saponins. Contracept., 2003; 68 (2): 135-38.

[8] Ibrahim M, Khan AA, Tiwari SK, Habeeba M.A, Khaja MN, Habibullah CM. Antimicrobial activity of Sapindus mukorossi and Rheum emodi extracts against Helicobacterium pylori in in vivo studies. World J. Gastroenterol.; 2006; 12(44): 7136-42.

[9] Tamura Y, Mizutani K, Ikeda T, Ohtani K, Kasai R, et al. Antimicrobial activities of saponins of pericarps of Sapindus mukurossi on dermatophytes. Nat. Med., 2001; 55 (1): 11-16.

[10]Singh J, Tripathi NN. Efficacy of plant extracts against Fusarium oxysporum $\mathrm{f}$. sp. lentis of Lens esculanta. J. Indian Bot. Soc., 1993; 72: 51-53.

[11]Grover RK, Moore JD. Toximetric studies of fungicides against brown rot organism Sclerotina fructicola and S. laxa. Phytopathology, 1962; 52: 876-80.

[12]Vincent JM. Distortion of fungal hyphae in the presence of certain inhibitions. Nature, 1927; 159: 850.

[13] Hossain, MA, Nagooru MR. Biochemical profiling and total flavonoids contents of leaves crude extract of endemic medicinal plant Corydyline terminalis $\mathrm{L}$. Kunth. Pharmacogn. J., 2011; 3(24): 25-29.

[14]Suresh SN, Nagarajan N. Preliminary phytochemical and antimicrobial activity analysis of Begonia malabarica Lam. J. Basic Appl. Biol., 2009; 3(1\&2): 59-61. 
[15]Tsuzuki JK, Svidzinski IE, Shinobu CS, Silva FA, Filho $E R$, et al. Antifungal activity of the extracts and saponins from Sapindus Saponaria L. An. Acad. Bras. Cienc., 2007; 79(4): 1-7.
[16] Garcia A, Rhoden SA, Bernardi-Wenzel J, Orlandelli RC, Azevedo JL, Pamphile JA. Antimicrobial activity of crude extracts of endophytic fungi isolated from medicinal plant Sapindus saponaria L. J. Appl. Pharm. Sci., 2012; 2(10): 35-40. 